\title{
Study on Mechanical Properties of PET Fiber-Reinforced Coal Gangue Fine Aggregate Concrete
}

\author{
Yanlin Huang (i) and An Zhou (iD \\ College of Civil Construction and Environment, Hubei University of Technology, Wuhan 430068, China \\ Correspondence should be addressed to Yanlin Huang; 291671351@qq.com
}

Received 30 November 2020; Revised 16 December 2020; Accepted 21 December 2020; Published 5 January 2021

Academic Editor: Bin Gong

Copyright (C) 2021 Yanlin Huang and An Zhou. This is an open access article distributed under the Creative Commons Attribution License, which permits unrestricted use, distribution, and reproduction in any medium, provided the original work is properly cited.

\begin{abstract}
In recent years, with the rapid development of the construction industry, the demand for natural river sand has become increasingly prominent. Development of alternatives to river sand has become an interesting direction for concrete research. In this paper, coal gangue was proposed to replace part of the river sand to produce coal gangue fine aggregate concrete, while waste polyethene terephthalate (PET) bottles were used as raw materials to make PET fibers to improve the mechanical properties of coal gangue fine aggregate concrete. There were two parts of the test conducted. In the first part, the compressive strength of the gangue fine aggregate concrete cube, splitting tensile strength, axial compressive strength, and static elastic modulus were studied when the substitution rate of coal gangue increased from $0 \%$ to $50 \%$. Referring to the equation of the full stress-strain curve of plain concrete, the stress-strain constitutive equation of coal gangue fine aggregate concrete was analyzed and studied. By comparing with plain concrete, it was found that the coal gangue concrete with a replacement rate of $50 \%$ had higher compressive strength and tensile strength, but its brittleness was significantly greater than that of plain concrete in the later stage. In the second part, by studying the effect of different PET fiber content on the mechanical properties of coal gangue fine aggregate concrete with a replacement rate of $50 \%$, it was found that when the addition of PET fiber was $0.1 \%$ and $0.3 \%$, not only were compressive strength, splitting tensile strength, static elastic modulus, and flexural strength of the gangue fine aggregate concrete effectively improved but also the brittleness of concrete can be significantly reduced. The study found that after adding $0.3 \%$ PET fiber, the coal gangue fine aggregate concrete with a replacement rate of $50 \%$ has better mechanical properties and less brittleness.
\end{abstract}

\section{Introduction}

Coal gangue is a kind of solid waste with low carbon content and hard texture produced in the process of coal mining [1]. In the long-term coal production process, China has deposited about 5 billion tons of coal gangue, and it is still increasing rapidly at a rate of about 200 million tons per year [2-4]. If a large amount of coal gangue cannot be used reasonably and efficiently, not only will a large amount of mountains and farmland be occupied, causing serious environmental pollution and resource waste, but also it is easy to cause natural disasters such as fires and mudslides $[4,5]$. Coal gangue contains a certain amount of active $\mathrm{SiO}_{2}$ and $\mathrm{Al}_{2} \mathrm{O}_{3}$ [6], and its main chemical composition is similar to a natural aggregate $[7,8]$, indicating that coal gangue can be used as a substitute for a concrete fine aggregate [2]. The active $\mathrm{SiO}_{2}$ and
$\mathrm{Al}_{2} \mathrm{O}_{3}$ in cement can produce secondary hydration reaction with cement to further improve the microstructure of concrete $[9,10]$. Coal gangue instead of a natural aggregate for concrete production is an interesting research field. Scholars domestically and internationally have done some related research in this field and achieved certain results, which have made great contributions to promoting the application of coal gangue in the construction field. For example, adding a certain amount of fine coal gangue to cement can significantly increase the slump and pumpability of the cement [11], but when the amount of fine coal gangue in the cement gangue backfill increases from $40 \%$ to $60 \%$, the strength of the cement coal gangue backfill decreases with the increase in the fine coal gangue content [12]. Li et al. applied the cleaned and crushed coal gangue material to the railway subgrade and found that the dynamic stiffness $\mathrm{K} 30$ of the coal 
gangue was greater than $130 \mathrm{MPa} \cdot \mathrm{m}^{-1}$, which met the requirements of high-speed railway subgrade [13]. Zhang et al. [14] found that the particle size distribution of the coal gangue coarse aggregate has limited influence on the mechanical properties of concrete. When coal gangue is used to replace all concrete coarse aggregates, the compressive strength of coal gangue coarse aggregate concrete was reduced by $19.4 \%$ compared with that of plain concrete. As the percentage of coal gangue replacement increases, the axial compression failure mode of coal gangue coarse aggregate concrete will change from shear failure to longitudinal split failure [8]. When studying the influence of coal gangue calcination temperature, calcination time, and fineness modulus on the mechanical properties of concrete, Dong et al., Yang et al., and Wang and Zhao found that the gangue fineness modulus is 1.9, and when the calcination temperature is $700^{\circ} \mathrm{C}$, the gangue is fine. Aggregate concrete mortar has the highest compressive strength [4]; coal gangue is calcined at a temperature of $750^{\circ} \mathrm{C}$ for 10 minutes, and the $28 \mathrm{~d}$ compressive strength of coal gangue aggregate concrete is about 39\% higher than that of natural coal gangue concrete [15]. When the gangue aggregate Fuller gradation curve index $(n)$ is 0.62 , the porosity of concrete is the lowest and the density is the highest. The compressive strength of $28 \mathrm{~d}$ coal gangue aggregate concrete can reach $37 \mathrm{MPa}$, which meets the strength requirements of C30 ordinary concrete [16]. Qiu et al. [17] studied the influence of coal gangue coarse aggregate replacement rate on concrete freeze resistance and established a CGC freeze-thaw damage evolution model. They found that when the coal gangue replacement rate is less than $40 \%$, CGC can better meet the freeze. It is required that the freeze-thaw damage evolution model is in good agreement with the actual experimental data, which can effectively reflect the freeze-thaw damage development process of CGC in the freeze-thaw environment. However, Guan et al. [18] found that when the gangue replacement rate increased from $0 \%$ to $60 \%$, the frost resistance of coal gangue concrete was significantly reduced, and the physical and mechanical properties of coal gangue concrete decreased with the extension of the freeze-thaw cycle time [19]. At the same time, Luo et al. [20] studied the influence of steel fiber content and shape on the compressive strength and split tensile strength of coal gangue concrete after freezing and thawing. They found that when the volume of corrugated steel fiber is $1 \%$, the compressive and tensile strength of the coal gangue concrete decreases the least after freezing and thawing. After freezing and thawing, the reduction in compressive and tensile strength is the smallest. Wang et al. [21] found that the water-cement ratio, sand ratio, and steel fiber content have a certain effect on the brittleness of coal gangue ceramsite lightweight aggregate concrete. When the water-cement ratio and sand ratio are greater than 0.32 and 0.38 , the brittleness increases with the decrease in the water-cement ratio and sand ratio, and when the steel fiber content is less than $1.5 \%$, the brittleness decreases with the increase in the steel fiber content.

By consulting domestic and foreign research literature, it is found that the current research is mainly concentrated on coal gangue aggregate concrete. The related research focused on the mechanical properties of coal gangue fine aggregate concrete and how to further improve the basic mechanical properties and toughness of coal gangue fine aggregate concrete. There is little and no application of PET fiber in coal gangue fine aggregate concrete. In order to analyze and study the effect of PET fiber on the mechanical properties of coal gangue fine aggregate concrete, we have conducted relevant understanding of PET materials by reading literature and other methods. It was discovered that PET is a compound polymer with strong corrosion resistance, fatigue resistance, and flexural properties. If a large number of PET packaging products cannot be recycled well, it is not only a waste of resources but also serious environmental pollution [22, 23]. Processing PET packaging products into fibers to make PET fiber concrete not only can increase the utilization rate of PET but also has a certain effect in improving the mechanical properties of concrete. Related research is as follows: Pereira et al. [24] studied the influence of length and content of fiber on the mechanical properties of concrete and found that when the volume ratio of PET was $0.2 \%$, the concrete tensile strength decreased with the increase in PET length. When the length was increased from $10 \mathrm{~mm}$ to $20 \mathrm{~mm}$, the concrete tensile strength decreased by 3.09 MPa. Moreover, the incorporation of PET can enhance the compressive strength of concrete, which is similar to the results of Irwan et al. [25]. At the same time, the research results of Pereira et al. also showed that with the addition of $0.1 \%$ and $0.2 \%$ PET fibers, the compressive strength of concrete increased by about $15 \%$ and $10 \%$, respectively. But Nematzadeh et al. [26] processed PET material into fragments to replace part of the river sand and found that the compressive strength of concrete would be reduced. The research results of Jawad et al. [27] showed that PET powder was ground into powder and added to GFRP steel bars. It was found that PET powder can be used as a strength additive to increase the compressive strength of the reinforced concrete. Blanco et al. [28] studied the effect of replacing part of river sand with different amounts and shapes of PET materials on the electrochemical properties of steel bars in concrete and found that the samples with PET had a higher potential value than the control. Ochi et al. [29] studied the influence of fiber content on the workability and compressive strength of concrete under different water-cement ratios. It was found that when $W / C=0.6$, the compressive strength of concrete was about $13.8 \%$ higher than that of ordinary concrete after adding 1\% of PET. $0.3 \%$ of PET can increase the workability of concrete and PET. Taghreed and Mohammed [30] added PET fiber to the concrete beam and found that the failure mode of the concrete beam changed from shear to bending. When the volume of PET fiber was $1 \%$, the shear capacity of the reinforced concrete beam increased by $11.1 \%$, And when the PET content is $1.25 \%$, the direct shearing capacity is increased by $43.5 \%$. But Khalid et al. [31] found that adding PET fiber to concrete does not significantly change the failure mode of reinforced concrete beams but only improves the results of the first crack load. Alani et al. [32] found that adding $1 \%$ PET fiber to concrete can increase the flexural strength of GUHPPCC beams by about $63.24 \%$ compared with 90-day-old ultra-high-performance concrete, and adding PET fiber can significantly improve the bending 
resistance and ductility of GUHPPCC flat panel. The research results of Al-Hadithi et al. [33] also showed that the incorporation of PET fiber into the SCC board can significantly improve the energy absorption capacity of the board and increase the compressive strength and flexural strength of the SSC board. At the same time, Fadadu et al. [34] found that compared with plain concrete, PET concrete exhibits higher ductility under cyclic loading. However, Mohammed et al. [35] found that the addition of PET fiber could not improve the ultimate bearing capacity of concrete beams but only improved the crack resistance of the beams. Through the above research results, it can be found that the reasonable use of PET materials in the concrete field can improve some physical properties of concrete to a certain extent.

The purpose of this experiment is to develop a new type of concrete by taking the place of concrete fine aggregate with coal gangue and optimizing with recycled PET fiber. The test includes two parts: the first part mainly studied the influence of coal gangue replacement rates of $10 \%, 20 \%, 30 \%, 40 \%$, and $50 \%$ on the compressive strength, splitting tensile strength, axial compressive strength, and static elastic modulus. In the second part, in order to reduce the brittleness of concrete, three groups of coal gangue fine aggregate concrete with different amounts of PET fiber were designed to study the effect of the amount of PET fiber on the mechanical properties and brittleness of the concrete. Finally, the relationship between split tensile strength and axial compressive strength and the relationship between axial compressive strength and cubic compressive strength were discussed and analyzed. The research results showed that the coal gangue replacement rate of $50 \%$ had better mechanical properties and less brittleness after adding $0.3 \%$ PET fiber.

\section{Test Material and Method}

2.1. Test Material. In this paper, the P.O42.5 ordinary Portland cement produced by China Huaxin Co., Ltd. was adopted, and its chemical composition complies with China's GB175-2007 standard [36]. The coarse aggregate was crushed with a continuous grading mechanism, the particle size range is $5-25 \mathrm{~mm}$, and the water absorption rate is $1.81 \%$. The fine aggregate is natural river sand, and the fineness modulus is 2.92; the moisture content and the water absorption rate are $2.51 \%$ and $7.58 \%$, respectively. Both the coarse aggregate and the fine aggregate meet the requirements of the Chinese GB50086-2001 standard [37]. The water used for mixing and curing is local drinking water with a $\mathrm{pH}$ value of 6.7 and a chloride and sulfate content of $250 \mathrm{mg} / \mathrm{L}$, which meets the Chinese JGJ 63-2006 standard [38]. The coal gangue used in this experiment was produced at the Woyang Mineral Processing Plant in Lingshou County, China, and its diameter ranges from 2 to $4 \mathrm{~cm}$. In order to make coal gangue stones into coal gangue fine aggregates, the coal gangue stones were firstly crushed with a jaw crusher; then, coal gangue particles with a diameter less than $4.75 \mathrm{~mm}$ were screened by using a vibrating sand screen, and finally, the coal gangue fine aggregate with a fineness modulus of 3.42 was manually made, as shown in Figure 1. The PET materials come from bottles of China Resources C'est-

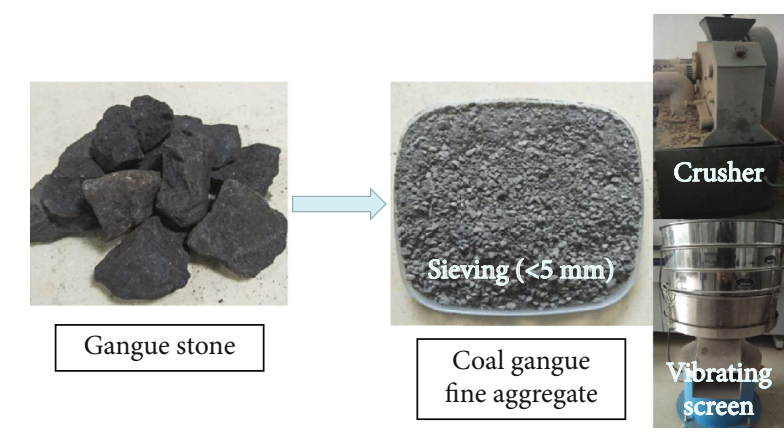

FIGURE 1: Screening process of coal gangue.

bon Beverage Co., Ltd., which were hand-cut into PET fibers with a length of $14-16 \mathrm{~mm}$ and a width of 3-5 $\mathrm{mm}$, and they were washed and dried (Figure 2).

2.2. Test Method. This study mainly includes two parts: first, a preliminary evaluation of the effect of replacing part of river sand with coal gangue and then a series of tests on PET fiber-reinforced coal gangue concrete. According to the Chinese GB/T 50081-2002 standard [39], the concrete test block for the first part of the test was made into two kinds of size of $100 \mathrm{~mm} \times 100 \mathrm{~mm} \times 100 \mathrm{~mm}$ and $100 \mathrm{~mm}$ $\times 100 \mathrm{~mm} \times 300 \times \mathrm{mm}$, in which the cube specimen was used to test cube compression and split tensile strength and the prism specimen was used for axial compression test and static pressure modulus test (Figure 3). At the same time, in order to draw the axial compressive stress-strain curve of concrete, it is necessary to use a displacement meter to collect the vertical deformation of the prism specimen (Figure 4). In the second part, in order to study the effect of PET fiber on the flexural properties of concrete, the flexural test of concrete was conducted on the specimen with the size of $100 \mathrm{~mm} \times 100 \mathrm{~mm} \times 400 \mathrm{~mm}$ (Figure 5); other tests were the same as the first part. All the specimens need to be cured for 28 days in an environment with a temperature of $20 \pm 2^{\circ} \mathrm{C}$ and a relative humidity more than $95 \%$ in advance.

\section{Test Design and Results of the First Part}

In order to study the impact of coal gangue on the mechanical properties of concrete, six fine aggregate replacement rates of $0 \%, 10 \%, 20 \%, 30 \%, 40 \%$, and $50 \%$ were designed in the first part of the experiment. The detailed mixing ratio is shown in Table 1.

3.1. Cube Compressive Strength and Split Tensile Strength. 36 cube specimens were equally divided into two parts to carry out the compressive test and split tensile strength test, respectively, whose variation is shown in Figure 6.

As shown in Figure 6, when the gangue replacement rate changed from $10 \%$ to $40 \%$, the compressive strength of concrete cubes first decreased and then increased with the increase in the gangue replacement rate, which was smaller than that of plain concrete. When the replacement rate increased from $40 \%$ to $50 \%$, the compressive strength was 


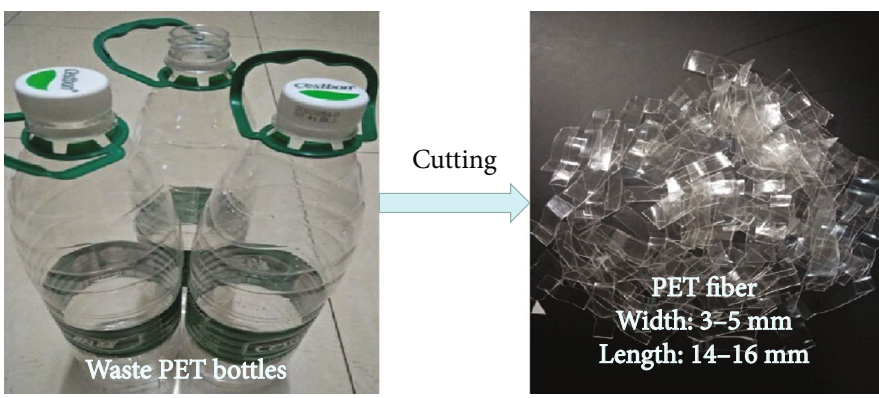

Figure 2: Cutting PET bottles for PET fiber.

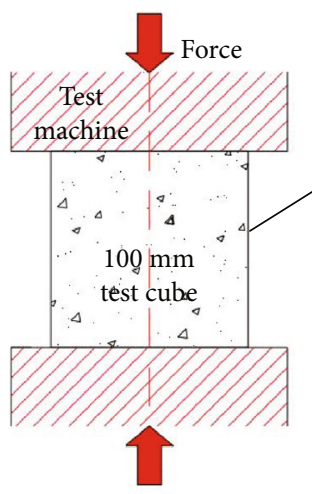

(a) Compressive test

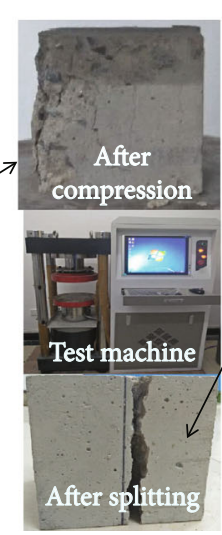

Atter sing

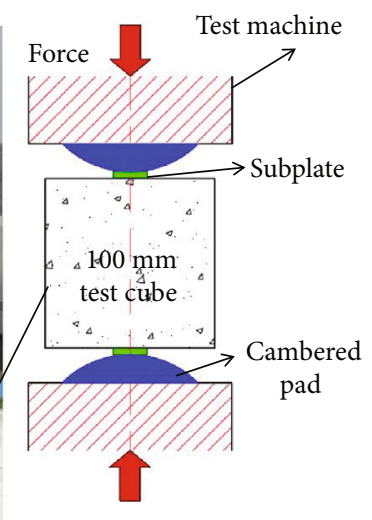

(b) Splitting test

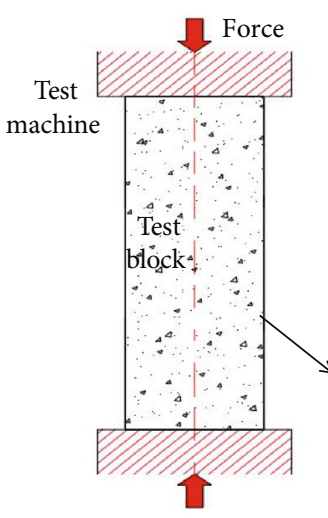

(c) Axial compression test

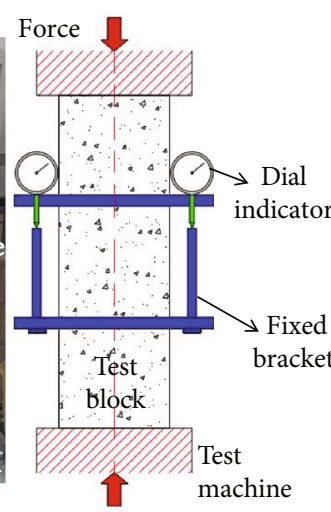

(d) Elastic modulus test

FIgURE 3: Test of cube compressive strength (a), splitting strength (b), axial compressive strength (c), and elastic modulus (d).

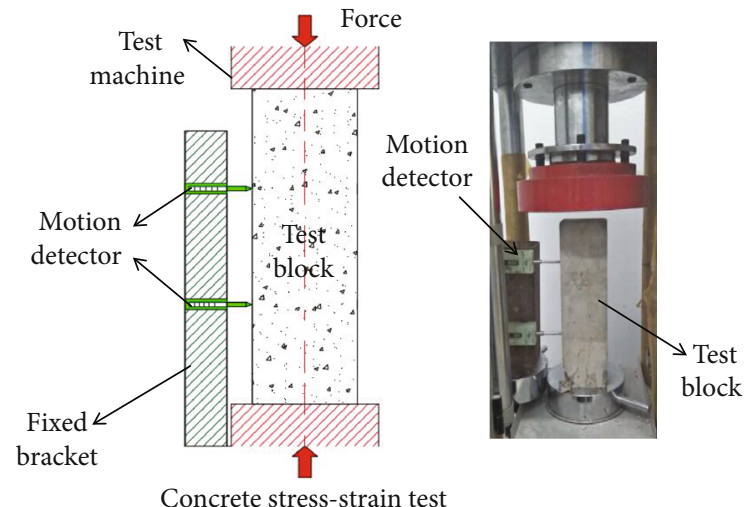

Figure 4: Test of concrete stress-strain.

increased by $8.7 \%$ compared to that of plain concrete, which is mainly because $\mathrm{SiO}_{2}$ in coal gangue can promote the secondary hydration reaction of cement and the calcium silicate produced made the interior of the concrete more compact [40]. At the same time, because of the high water absorption rate of coal gangue, the water-cement ratio of concrete decreased with the increases in the replacement amount of coal gangue, and appropriately reducing the water-cement ratio can increase the strength of concrete [41]. The splitting tensile strength of CGC tended first to decrease and then increase with the increase in coal gangue replacement rate. When the coal gangue replacement rate was $50 \%$, the CGC tensile strength reached the highest value of $3.8 \mathrm{MPa}$, which was about 1.2 times that of plain concrete. T1he main reason is similar to the compressive strength of the CGC cube.

3.2. Axial Compressive Strength and Static Elastic Modulus. 36 prism specimens were equally divided into two parts to carry out the axial compression test and static compression elastic modulus test, respectively. At the same time, in order to more directly reflect the influence of the coal gangue replacement rate on the static elastic modulus of concrete, the elastic modulus of each group of the gangue fine aggregate concrete was compared with the elastic modulus of the plain concrete with a $0 \%$ replacement rate; their variation trend is shown in Figure 7.

As shown in Figure 7, the axial compressive strength of concrete decreased first and then increased with the increase in coal gangue replacement rate. When the replacement rate of coal gangue was $10 \% \sim 40 \%$, the axial compressive strength was smaller than that of plain concrete. When the replacement rate increased from $40 \%$ to $50 \%$, the compressive strength of concrete significantly increased and was greater than that of plain concrete, and the main reason was similar to the compressive strength of concrete cubes. When the replacement rate of coal gangue increased from $10 \%$ to $50 \%$, the elastic modulus of concrete was lower than that of plain concrete. When the replacement rate reached $50 \%$, the elastic modulus was the smallest. At the same time, as the axial compressive strength of coal gangue fine aggregate 


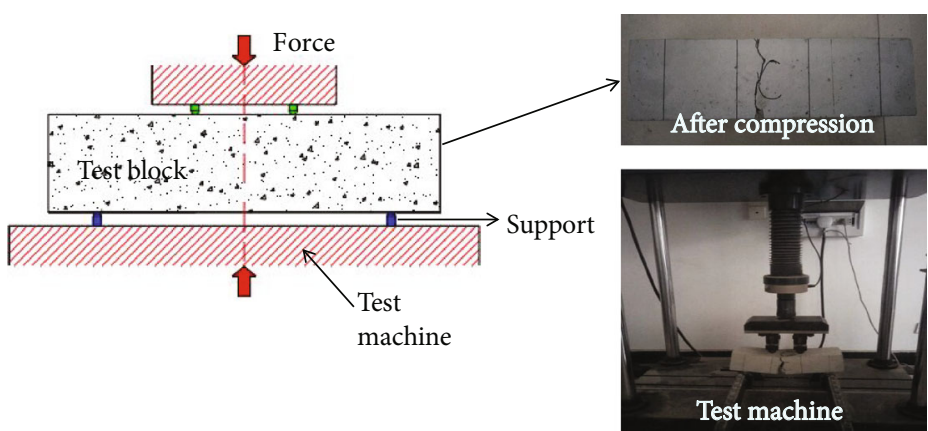

Flexural strength test

FIgURE 5: Test of flexural strength.

TABLE 1: Concrete mix proportion.

\begin{tabular}{|c|c|c|c|c|c|c|c|}
\hline \multirow[b]{2}{*}{ Specimen } & \multirow[b]{2}{*}{$\begin{array}{c}\text { Replacement rate } \\
(\%)\end{array}$} & \multirow[b]{2}{*}{$\begin{array}{l}\text { Cement } \\
\left(\mathrm{kg} \cdot \mathrm{m}^{-3}\right)\end{array}$} & \multirow[b]{2}{*}{$\begin{array}{c}\text { Water } \\
\left(\mathrm{kg} \mathrm{m}^{-3}\right)\end{array}$} & \multirow[b]{2}{*}{$\begin{array}{c}\text { Coarse aggregate } \\
\left(\mathrm{kg} \cdot \mathrm{m}^{-3}\right)\end{array}$} & \multicolumn{2}{|c|}{ Fine aggregate } & \multirow[b]{2}{*}{$\begin{array}{c}\text { Water reducer } \\
\left(\mathrm{kg} \cdot \mathrm{m}^{-3}\right)\end{array}$} \\
\hline & & & & & $\begin{array}{c}\text { River sand } \\
\left(\mathrm{kg} \cdot \mathrm{m}^{-3}\right)\end{array}$ & $\begin{array}{l}\text { Coal gangue } \\
\left(\mathrm{kg} \cdot \mathrm{m}^{-3}\right)\end{array}$ & \\
\hline CGC-0 & 0 & 379.6 & 205 & 1151.31 & 619.9 & 0 & 1.63 \\
\hline CGC-1 & 10 & 379.6 & 205 & 1151.31 & 619.9 & 59.56 & 1.63 \\
\hline CGC-2 & 20 & 379.6 & 205 & 1151.31 & 619.9 & 119.13 & 1.63 \\
\hline CGC-3 & 30 & 379.6 & 205 & 1151.31 & 619.9 & 178.69 & 1.63 \\
\hline CGC-4 & 40 & 379.6 & 205 & 1151.31 & 619.9 & 238.25 & 1.63 \\
\hline CGC-5 & 50 & 379.6 & 205 & 1151.31 & 619.9 & 297.81 & 1.63 \\
\hline
\end{tabular}

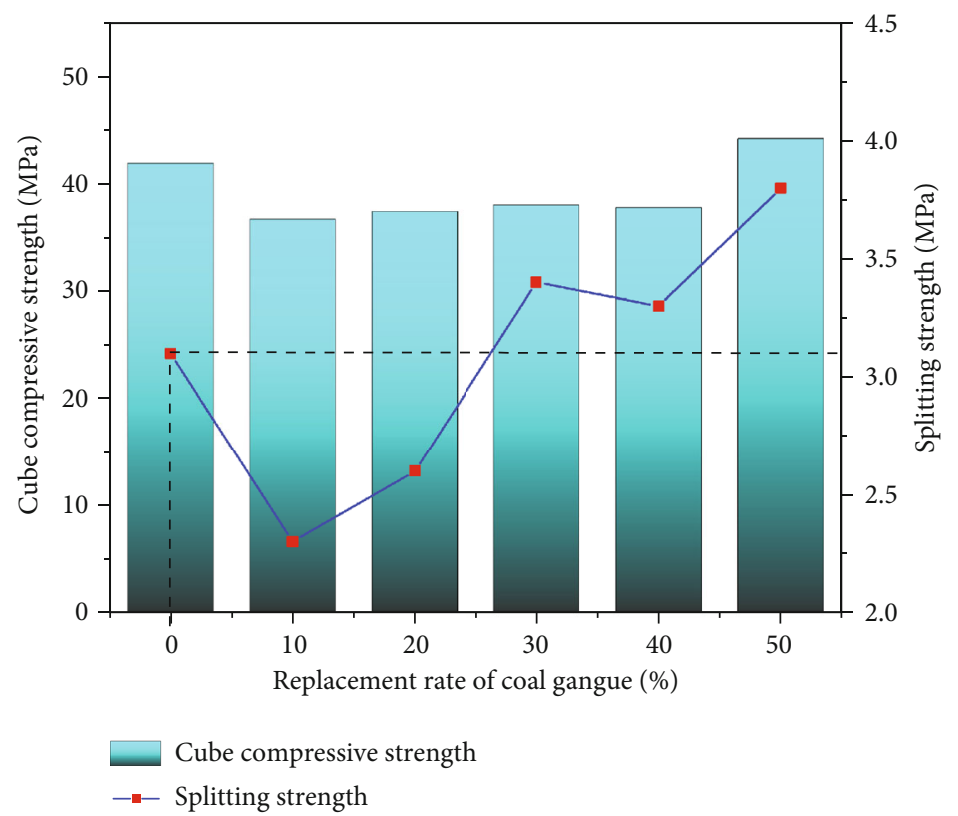

FIGURE 6: Cube compressive strength and splitting tensile strength of coal gangue fine aggregate concrete.

concrete increased, its elastic modulus decreased continuously; this is contrary to the characteristic that the elastic modulus of plain concrete increases with the increase in compressive strength. The main reason is that the texture of coal gangue is soft, with the increase in the coal gangue replacement rate; the number of hard river sand particles decreased, resulting in a relatively large deformation of
CGC when the concrete was subjected to equivalent pressure changes. According to the elastic modulus calculation (Equation (1)), when the pressure value of $\left(F_{\alpha}-F_{0}\right)$ remained unchanged, the larger the $\Delta_{n}$, the smaller the elastic modulus.

$$
E_{\mathrm{c}}=\frac{\left(F_{\alpha}-F_{0}\right) L_{n}}{A \times \Delta_{n}}
$$




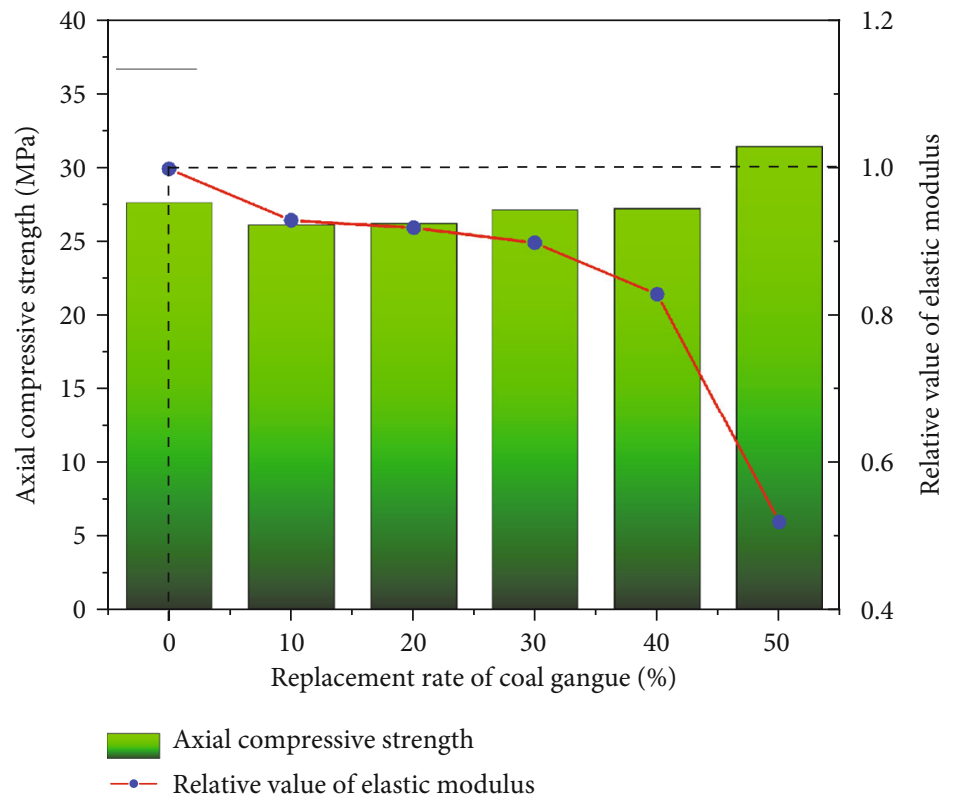

Figure 7: Axial compressive strength and elastic modulus of coal gangue fine aggregate concrete.

where $E_{c}$ is the elastic modulus of concrete, $F_{\alpha}$ is the load when the stress equals to $1 / 3$ of the axial compressive strength, $F_{0}$ is the initial load when the stress is $0.5 \mathrm{MPa}, L_{n}$ is the gauge distance, $A$ is the bearing area of the specimen, and $\Delta_{n}$ is the deformation difference when the specimen is loaded from $F_{0}$ to $F_{\alpha}$.

3.3. Axial Compressive Stress-Strain Curve. The study of the axial compressive stress-strain curve of $100 \mathrm{~mm} \times 100 \mathrm{~mm} \times$ $300 \mathrm{~mm}$ specimens includes three main steps. First, measure the vertical compression variable and relative pressure value of the concrete; then, calculate the stress and strain of the concrete by Equation (2); finally, the stress and strain of coal gangue fine aggregate concrete were processed in a dimensionless manner by using $\sigma / \sigma_{\mathrm{c}}$ and $\varepsilon / \varepsilon_{\mathrm{c}}\left(\sigma_{\mathrm{c}}\right.$ and $\varepsilon_{\mathrm{c}}$ represent the peak stress and peak strain, respectively; $\sigma$ and $\varepsilon$ represent the real-time stress and real-time strain, respectively) $[42,43]$, and the stress ratio and strain ratio were calculated. The processing results are shown in Figure 8.

$$
\begin{aligned}
\sigma & =\frac{F}{A}, \\
\varepsilon & =\frac{\Delta L}{L},
\end{aligned}
$$

where $\sigma$ is the stress, $\varepsilon$ is the strain, $F$ is the axial compression ( $\mathrm{MPa}), A$ is the area of the compression surface of the specimen $\left(\mathrm{mm}^{2}\right), \Delta L$ is the vertical compression variable $(\mathrm{mm})$, and $L$ is the vertical height of the original test piece $(\mathrm{mm})$.

As shown in Figure 8, when the coal gangue replacement rate increased from $10 \%$ to $50 \%$, the stress-strain curve of the rising section of CGC fitted well with that of ordinary concrete, indicating that in the elastic and elastoplastic stage, the deformation mechanism of CGC was similar to that of plain concrete. However, the descending curve of CGC was relatively scattered. When the replacement rate was 50\%, the downward trend was the steepest and the brittleness increased sharply. When the replacement rate was $10 \%$ and $20 \%$, the curve trend of CGC basically coincided with that of plain concrete. At the same time, it can be seen from Figure 8 that the stress-strain curve of CGC was similar to that of ordinary concrete; they all gone through the stages of elasticity, elastoplasticity, and yield failure [43]. Therefore, the approximate constitutive equation of CGC can be established according to the equation of full stress-strain curve of plain concrete $[42,43]$ (see Equation (3)). Through nonlinear fitting analysis, it was found that when $\alpha=1.02$ and $\beta=8.64$, the stress-strain constitutive equation of CGC was basically consistent with the experimental data. Therefore, $\alpha=1.02$ and $\beta=8.64$ can be used as the value of parameter of the stress-strain constitutive equation of coal gangue fine aggregate concrete. The fitting curve of the axial compressive stress-strain constitutive equation of coal gangue fine aggregate concrete can be obtained, as shown in Figure 9.

$$
\begin{aligned}
& y=\alpha x+(3-2 \alpha) x^{2}+(\alpha-2) x^{3} \quad(0 \leq x \leq 1), \\
& y=\frac{x}{\beta(x-1) x^{2}+x} \quad(x \geq 1),
\end{aligned}
$$

where $y$ is the stress ratio, $x$ is the strain ratio, and $\alpha$ and $\beta$ are the parameters of the curve equations of concrete rising and falling sections, respectively, where $\alpha=E_{0} / E_{p}$, in which $E_{0}$ and $E_{p}$ are the secant elastic modulus at $0.5 f_{c}$ and at peak stress, respectively; the value range of $\alpha$ is generally $[1,3]$, and the value range of $\beta$ is generally $[5,10][44,45]$.

\section{Test Design and Results of the Second Part}

In the first part of the test, it was found that when the replacement rate of coal gangue was $50 \%$, the cubic compressive 


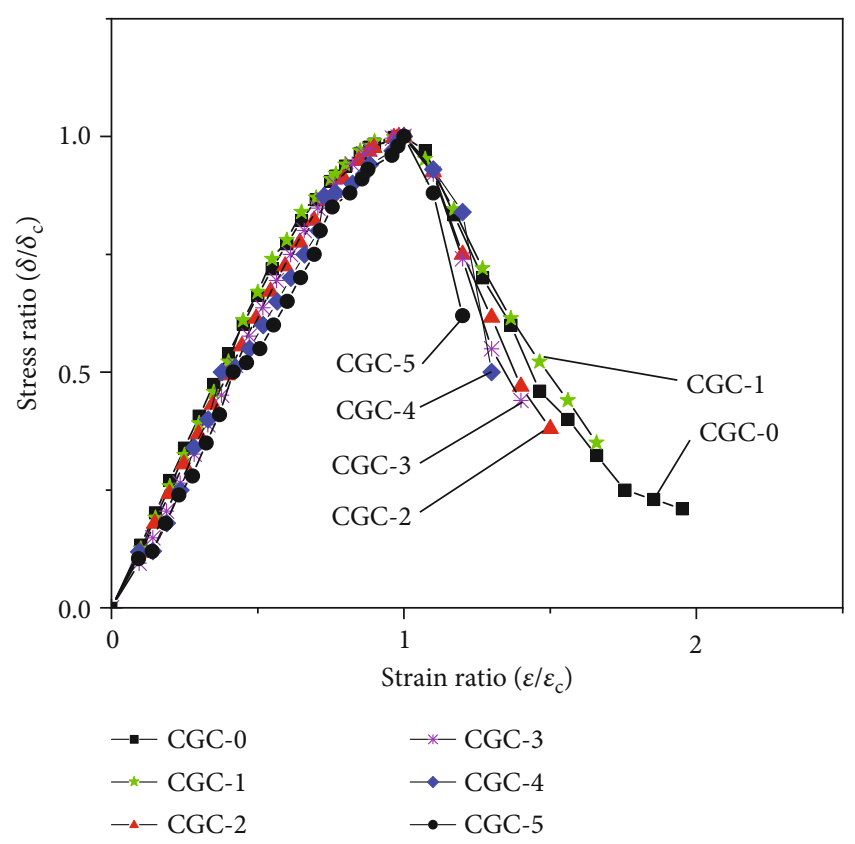

FIgURE 8: Complete stress-strain curve of concrete.

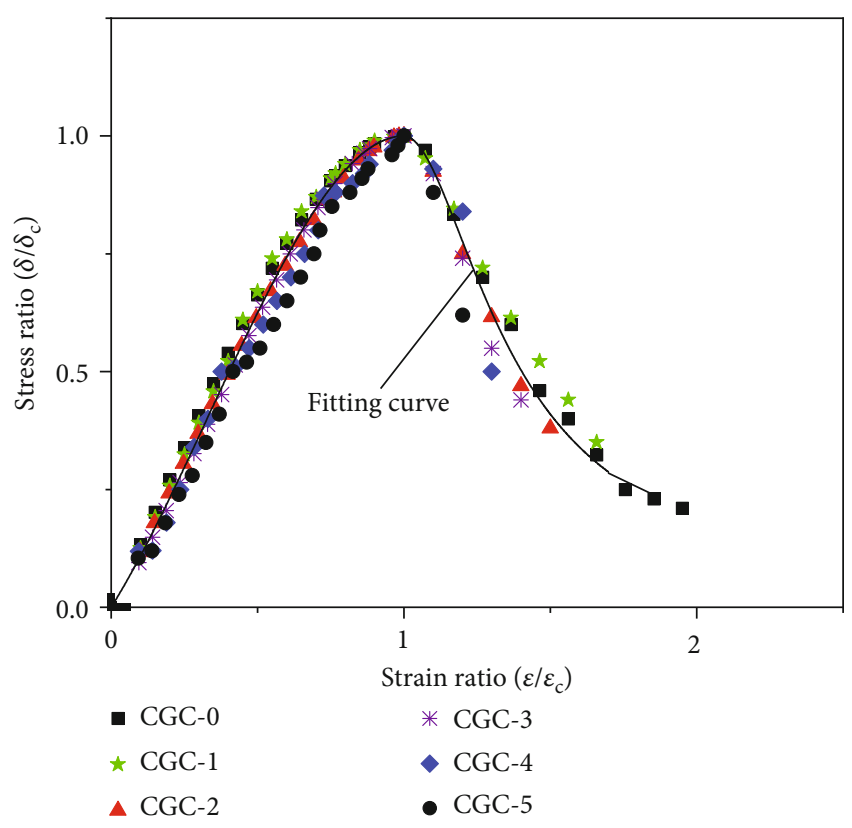

FIGURE 9: Fitting curve of the stress-strain constitutive equation of concrete.

strength, axial compressive strength, and splitting tensile strength of coal gangue fine aggregate concrete were all higher than those of plain concrete, but after the compressive strength and splitting tensile strength reached the peak point, the compressive and tensile properties in the later period dropped sharply. The brittleness of plain concrete increased significantly, which did not meet the low brittleness requirements of the Chinese GB50010-2010 specification [46-54]. However, adding an appropriate amount of fiber to concrete can enhance the strength and ductility of the concrete. There- fore, in the second part, based on the coal gangue fine aggregate concrete with a replacement rate of $50 \%$, three groups of coal gangue fine aggregate concrete with different PET fiber content of $0.1 \%, 0.3 \%$, and $0.5 \%$ were designed, respectively, to study the effect of PET fiber content on the mechanical properties and brittleness of coal gangue fine aggregate concrete. The concrete mix ratio is listed in Table 2.

4.1. Cube Compressive Strength and Split Tensile Strength. By conducting the compressive test and split tensile test on 24 cube specimens, the cubic compressive strength and split tensile strength of PET fiber-reinforced coal gangue fine aggregate concrete increased with the increase in PET fiber. The change trend chart is shown in Figure 10.

As shown in Figure 10, when the amount of PET fiber was $0.1 \%$ and $0.3 \%$, the cubic compressive strength and splitting tensile strength were both higher than those of CGC-5. When $0.1 \%$ PET fiber was added, the cubic compressive strength and split tensile strength were increased by $7.2 \%$ and $7.9 \%$, respectively, and increased by $13.1 \%$ and $32.2 \%$ compared to those of the plain concrete in Figure 6. However, when the amount of PET fiber increased from $0.3 \%$ to $0.5 \%$, the cubic compressive strength and split tensile strength of coal gangue fine aggregate concrete showed a downward trend, which was $9.1 \%$ and $26.3 \%$ lower than those of CGC-5.

4.2. Axial Compressive Strength and Static Elastic Modulus. By conducting the axial compression test and testing static elastic modulus of 24 prism specimens, the trend of the axial compressive strength and relative elastic modulus of PET fiber-reinforced coal gangue fine aggregate concrete was obtained and is shown in Figure 11.

As shown in Figure 11, when the PET fiber content was $0.1 \%$, the axial compressive strength and relative elastic modulus of concrete increased by $3.2 \%$ and $19.2 \%$, respectively, compared with those of CGC-5. When the amount of PET fiber was $0.3 \%$, the axial compressive strength of concrete was equal to that of CGC-5, but when the amount of fiber reached $0.5 \%$, the axial compressive strength of concrete decreased to be $8.9 \%$ lower than that of CGC-5. At the same time, when the amount of PET fiber was $0.1 \% \sim 0.5 \%$, the relative elastic modulus of concrete was larger than that of CGC-5. It can be seen that PET fiber can increase the elastic modulus of concrete.

4.3. Flexural Strength. In order to study the effect of PET fiber content on the flexural performance of concrete, three groups of coal gangue fine aggregate concrete with different PET fiber content were designed. In the flexural test, the change trend of the flexural strength of PET fiber-reinforced coal gangue fine aggregate concrete with the increase in PET fiber and the pressure-displacement curve of concrete were obtained, as shown in Figures 12 and 13.

As shown in Figure 12, the flexural strength of concrete increased first and then decreased with the increase in PET fiber content. The addition of $0.3 \%$ PET fiber can effectively increase the flexural strength of coal gangue fine aggregate concrete, which is $6.7 \%$ higher than that of CGC-5. However, 
TABLE 2: Concrete mix proportion.

\begin{tabular}{|c|c|c|c|c|c|c|c|}
\hline \multirow[b]{2}{*}{ Specimens } & \multirow[b]{2}{*}{$\begin{array}{c}\text { PET content } \\
(\%)\end{array}$} & \multirow[b]{2}{*}{$\begin{array}{l}\text { Cement } \\
\left(\mathrm{kg} \cdot \mathrm{m}^{-3}\right)\end{array}$} & \multirow[b]{2}{*}{$\begin{array}{c}\text { Water } \\
\left(\mathrm{kg} \cdot \mathrm{m}^{-3}\right)\end{array}$} & \multirow[b]{2}{*}{$\begin{array}{c}\text { Coarse aggregate } \\
\left(\mathrm{kg} \cdot \mathrm{m}^{-3}\right)\end{array}$} & \multicolumn{2}{|c|}{ Fine aggregate } & \multirow[b]{2}{*}{$\begin{array}{l}\text { Water reducer } \\
\left(\mathrm{kg} \cdot \mathrm{m}^{-3}\right)\end{array}$} \\
\hline & & & & & $\begin{array}{l}\text { River sand } \\
\left(\mathrm{kg} \cdot \mathrm{m}^{-3}\right)\end{array}$ & $\begin{array}{l}\text { Coal gangue } \\
\left(\mathrm{kg} \cdot \mathrm{m}^{-3}\right)\end{array}$ & \\
\hline CGC-5 & 0 & 379.6 & 205 & 1151.31 & 619.9 & 297.81 & 1.63 \\
\hline CGC-0.1 & 0.1 & 379.6 & 205 & 1151.31 & 619.9 & 297.81 & 1.63 \\
\hline CGC-0.3 & 0.3 & 379.6 & 205 & 1151.31 & 619.9 & 297.81 & 1.63 \\
\hline CGC-0.5 & 0.5 & 379.6 & 205 & 1151.31 & 619.9 & 297.81 & 1.63 \\
\hline
\end{tabular}

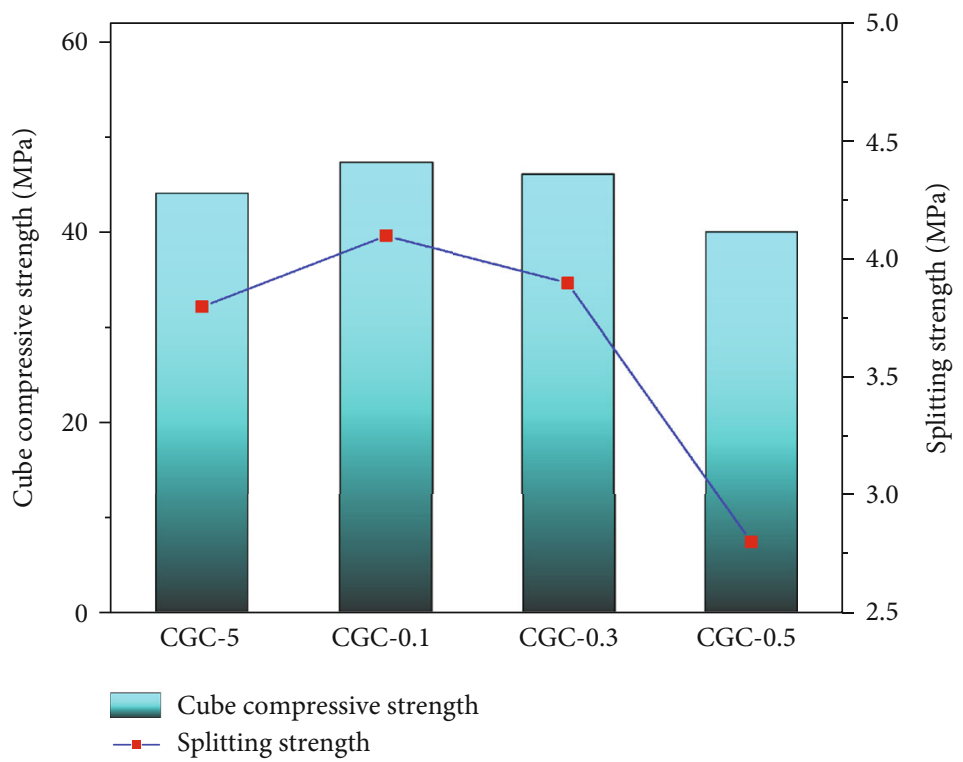

Figure 10: Cube compressive strength and splitting tensile strength of PET fiber-reinforced coal gangue fine aggregate concrete.

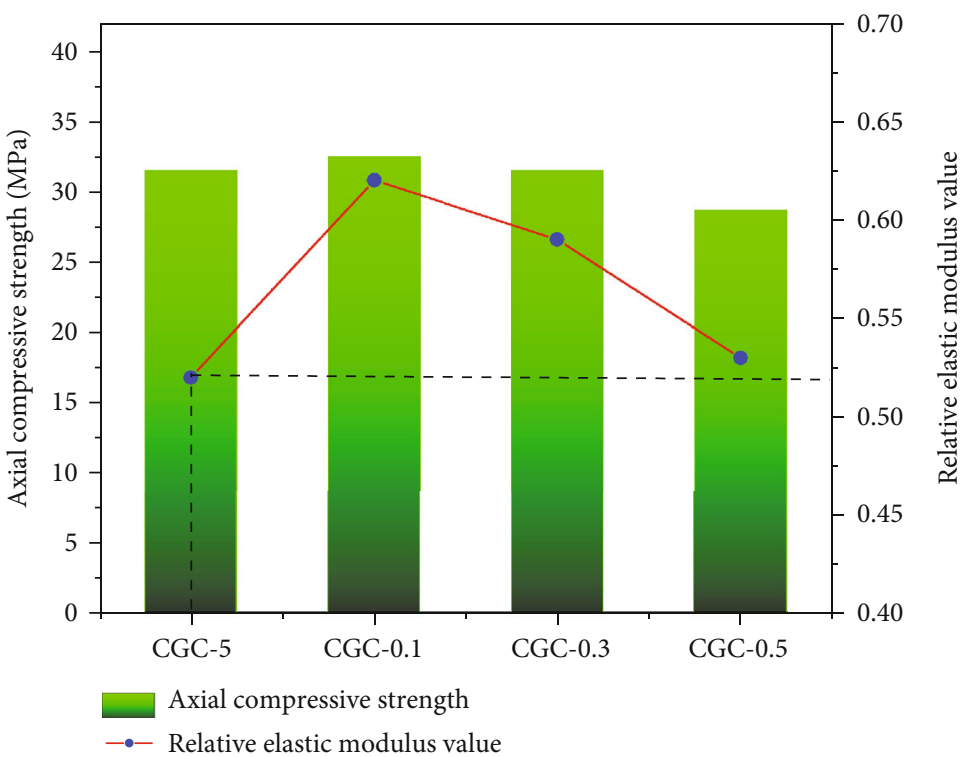

FIGURE 11: Axial compressive strength and elastic modulus of PET fiber-reinforced coal gangue fine aggregate concrete.

when the fiber content increased from $0.3 \%$ to $0.5 \%$, the compressive strength of concrete was reduced by about $8.1 \%$ compared with that of CGC-5. At the same time, it can be found from Figure 13 that with the increase in the PET fiber, the slope of the pressure-displacement curve continuously decreased, which indicated that PET fiber could obviously improve the ductility of coal gangue fine aggregate concrete before the concrete was broken. Among them, the $0.5 \%$ 


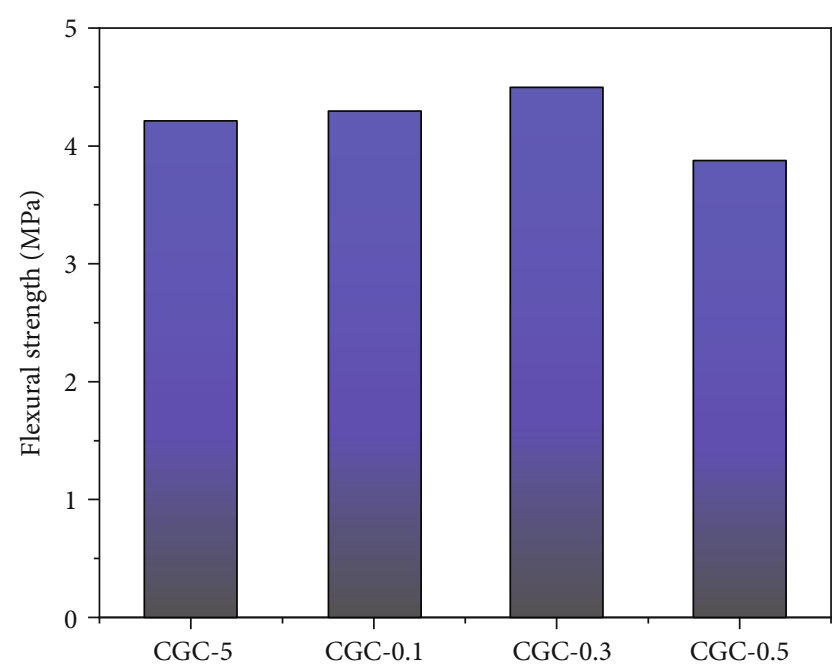

Figure 12: Flexural strength.

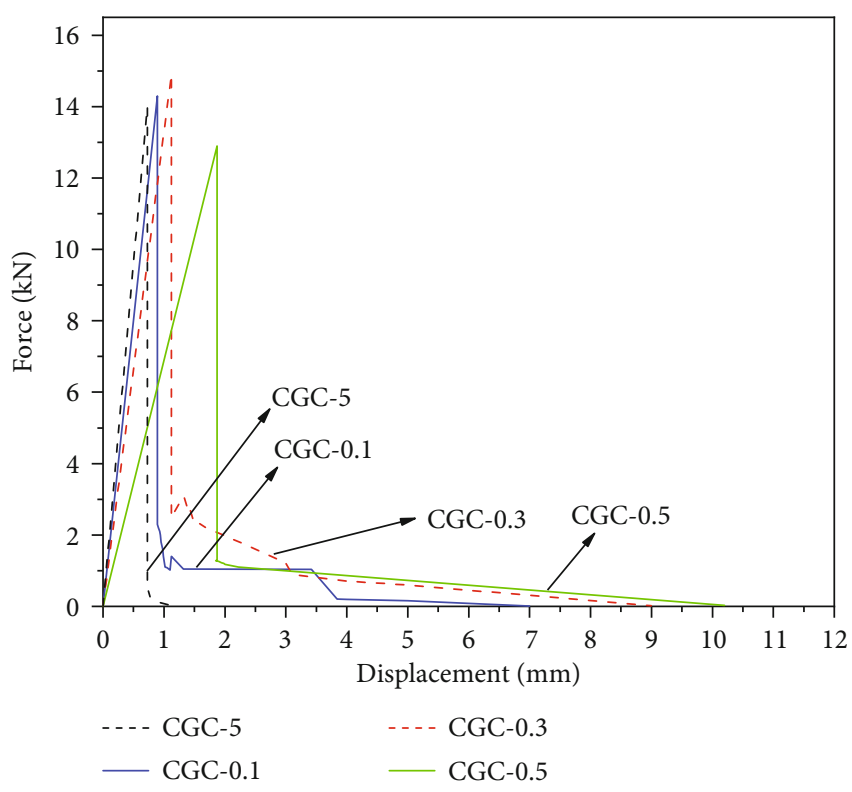

Figure 13: Pressure-displacement curve.

fiber-reinforced coal gangue fine aggregate concrete had the largest displacement of $1.87 \mathrm{~mm}$, which was 2.56 times that of CGC-5.

4.4. Axial Compressive Stress-Strain Curve. While studying the influence of different amounts of PET fiber on the axial compressive stress-strain curve of coal gangue fine aggregate concrete, the test data was processed by the method in the first part of the test, and the full curve of the axial compressive stress-strain of PET fiber reinforced coal gangue fine aggregate concrete and the fitted curve of the stress-strain constitutive equation were obtained and are shown in Figures 14 and 15.

As shown in Figure 14, when the amount of PET fiber was $0.1 \%, 0.3 \%$, and $0.5 \%$, the slope of the descending section of the stress-strain curve was gentler than that of CGC-5, and

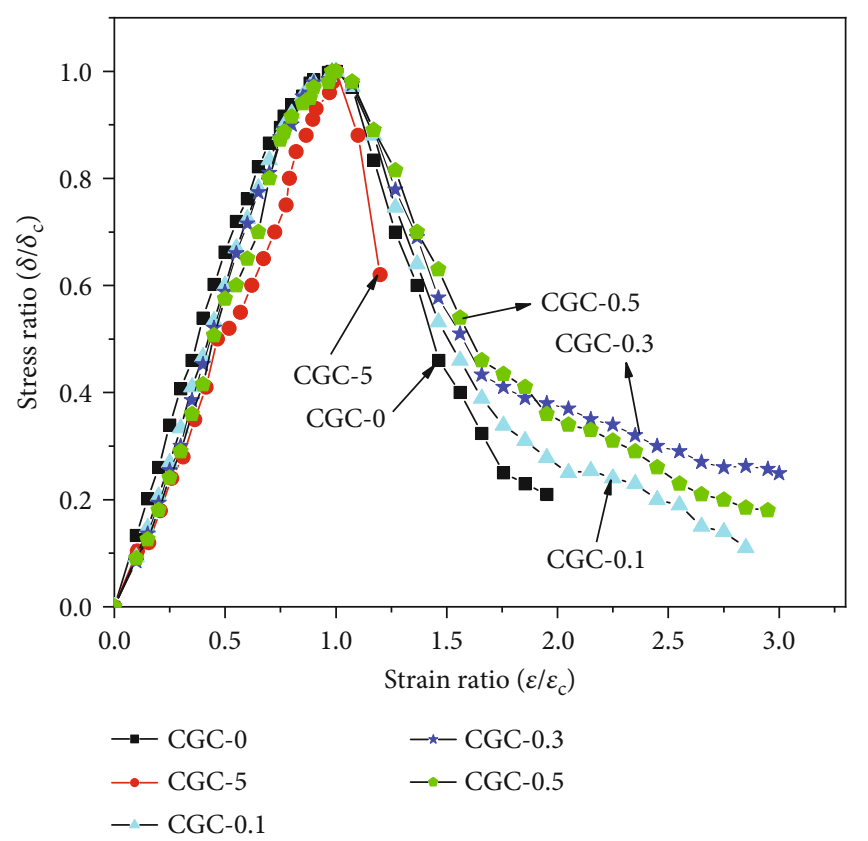

Figure 14: Complete stress-strain curve of concrete.

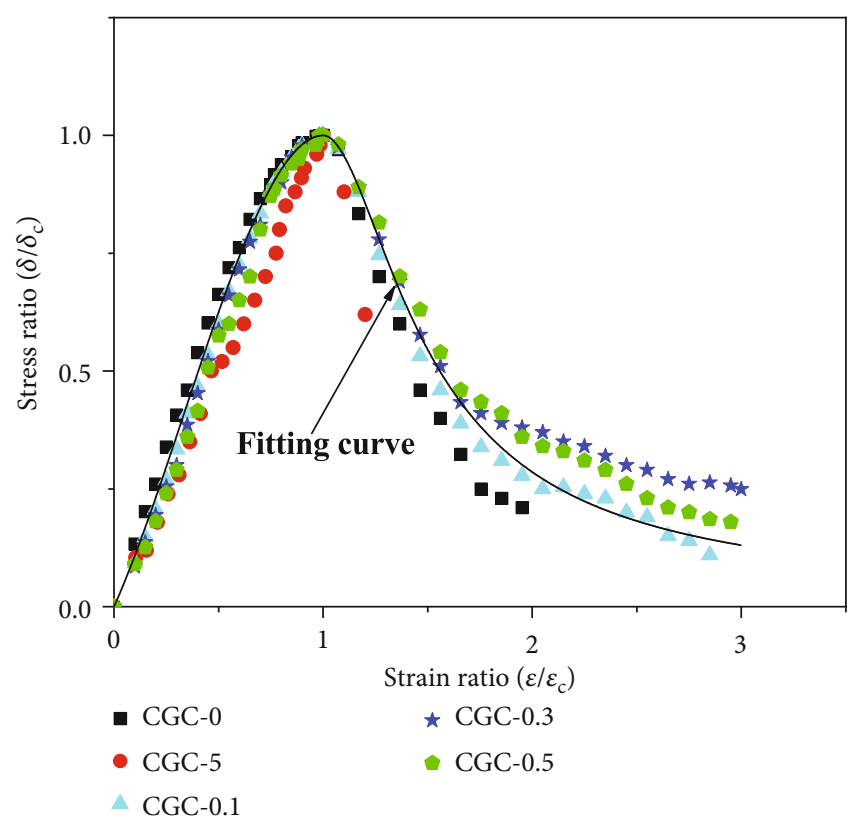

FIGURE 15: Fitting curve of the stress-strain constitutive equation of concrete.

the descending slope of CGC-0.3 was the gentlest. It can be seen that PET fiber can significantly reduce the brittleness of coal gangue fine aggregate concrete, and the reduction effect of $0.3 \%$ fiber content was the best. At the same time, through the nonlinear fitting analysis of the full stressstrain curve of concrete, it was found that when $\alpha=1.121$ and $\beta=5.517$, the axial compressive stress-strain constitutive equation is basically consistent with the test data. It can be seen that $\alpha=1.121$ and $\beta=5.517$ can be used as the parameters of the stress-strain constitutive equation of PET fiberreinforced coal gangue fine aggregate concrete. 


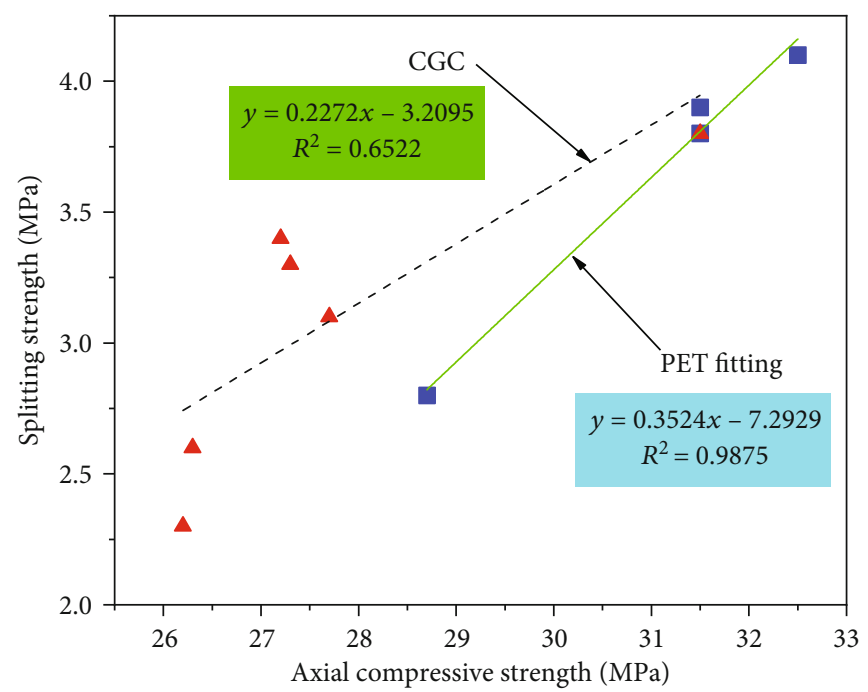

Figure 16: Relation between splitting tensile strength and cube compressive strength.

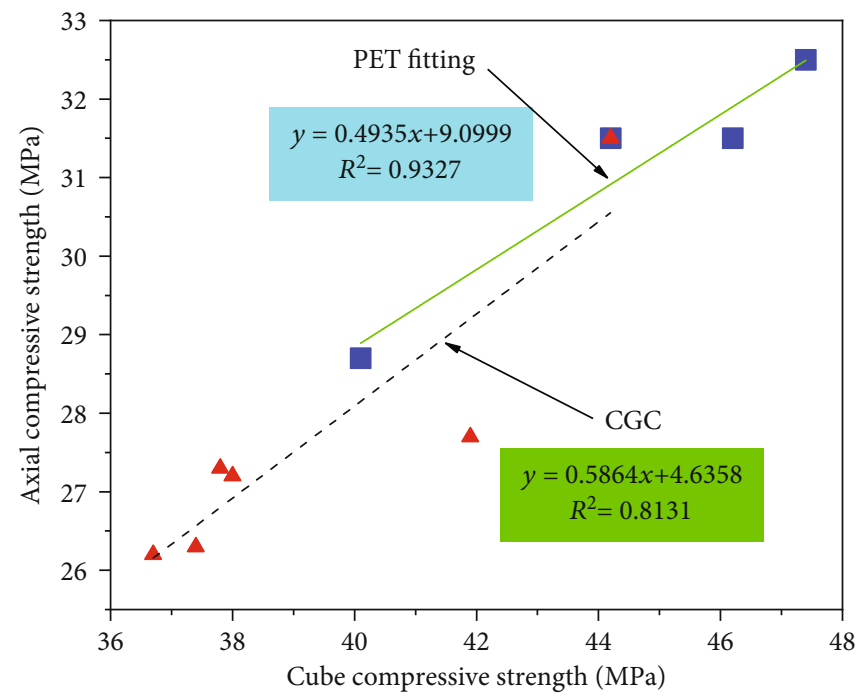

FIGURE 17: Relation between axial compressive strength and cube compressive strength.

\section{Correlation Discussion}

5.1. The Relationship between Split Tensile Strength and Axial Compressive Strength. After analyzing the relationship between the split tensile strength and axial compressive strength of concrete, the linear equations of the split tensile strength and axial compressive strength of coal gangue fine aggregate concrete and PET fiber-reinforced coal gangue fine aggregate concrete were obtained in Equations (4) and (5), respectively. The relationship between the split tensile strength and axial compressive strength is drawn in Figure 16.

$$
\begin{aligned}
& y=0.2272 x-3.2095, \\
& y=0.3524 x-7.2929,
\end{aligned}
$$

where $y$ is the splitting tensile strength (MPa) and $x$ is the axial compressive strength $(\mathrm{MPa})$.

As shown in Figure 16, the splitting tensile strength of concrete presented a positive linear relationship with the axial compressive strength. The determination coefficient $R^{2}$ of coal gangue fine aggregate concrete was equal to 0.6522 , which was much smaller than 0.9875 of PET fiberreinforced coal gangue concrete, which indicated that PET fiber had an obvious influence on the linear relationship between split tensile strength and axial compressive strength.

5.2. The Relationship between the Cube Compressive Strength and the Axis Compressive Strength. By analyzing the relationship between the cube compressive strength and the axial compressive strength, the linear equations for the compressive strength and axial compressive strength of the coal gangue fine aggregate concrete and PET fiber-reinforced coal 
gangue fine aggregate were obtained in Equations (6) and (7), respectively. The relationship between the cubic compressive strength and the axial compressive strength is drawn in Figure 17.

$$
\begin{aligned}
& y=0.5864 x+4.6358 \\
& y=0.4935 x+9.0999
\end{aligned}
$$

where $y$ is the axial compressive strength $(\mathrm{MPa})$ and $x$ is the cubic compressive strength ( $\mathrm{MPa})$.

As shown in Figure 17, the cubic compressive strength of concrete was positively proportional to the axial compressive strength, and the determination coefficient of the linear equation was greater than 0.8 , indicating that the linear equation fitted the actual data well.

\section{Conclusions}

(1) Through studying the influence of replacing part of river sand with coal gangue on compressive performance, tensile performance, and static elastic modulus of concrete, it was found that with the increase in the coal gangue replacement rate, the concrete cube compressive strength, the split tensile strength, and the axial compressive strength showed a trend of increasing first and then decreasing, while the static elastic modulus showed a decreasing trend. But when the replacement rate of coal gangue was $50 \%$, the cubic compressive strength, split tensile strength, and axial compressive strength of concrete reached their maximum values, which were, respectively, $5.2 \%, 22.6 \%$, and $13.7 \%$ higher than those of plain concrete. At the same time, when discussing the correlation between concrete axial compressive strength and cubic compressive strength, the axial compressive strength and the cubic compressive strength showed a linear relationship with the determination coefficient $R^{2}$ of 0.8131

(2) When analyzing the stress-strain curve of coal gangue fine aggregate concrete, it was found that when the replacement rate of coal gangue was $10 \%$, $20 \%$, and $30 \%$, the axial compressive stress-strain curve of coal gangue fine aggregate concrete was similar to that of plain concrete. Through fitting analysis, we found when $\alpha=1.02$ and $\beta=8.64$, the fitting curve obtained according to the standard concrete stress-strain curve equation was basically consistent with the test data of CGC. By taking the values $\alpha=$ 1.02 and $\beta=8.64$ as the parameters of the CGC stress-strain constitutive equation, the stress-strain constitutive equation of CGC which is similar to that of concrete can be obtained, and they both included stages of elasticity, elastoplasticity, and yield failure. However, when the coal gangue replacement rate was $40 \%$ and $50 \%$, the descending section of the curve of concrete was steeper, and its brittleness was significantly greater than that of plain concrete
(3) When studying the effect of PET fiber content on the mechanical properties of coal gangue fine aggregate concrete, it was found that after adding $0.1 \%$ PET fiber, the cubic compressive strength, splitting tensile strength, axial compressive strength, and flexural strength of concrete are increased by $7.2 \%, 7.9 \%$, $3.2 \%$ and $19.2 \%$, respectively, compared with those of CGC-5. However, when the content of PET fiber increased to $0.5 \%$, the cubic compressive strength, split tensile strength, axial compressive strength, and flexural strength of concrete decreased, which were, respectively, $9.3 \%, 26.3 \%, 8.9 \%$, and $8.1 \%$ lower than those of CGC-5. When the amount of PET fiber increased from $0.1 \%$ to $0.5 \%$, the static elastic modulus of concrete was higher than that of CGC-5. When the amount was $0.1 \%$, the static elastic modulus increased the most, which was $19.2 \%$ higher than that of CGC-5. It can be seen that by adding $0.1 \%$ or $0.3 \%$ of PET fiber in the coal gangue fine aggregate concrete with a replacement rate of $50 \%$, the mechanical properties of the concrete can be improved and the brittleness of the concrete was reduced

(4) According to the axial compressive stress-strain curve of PET fiber-reinforced coal gangue fine aggregate concrete, it can be found that the addition of $0.1 \%, 0.3 \%$, and $0.5 \%$ of PET fiber can significantly reduce the brittleness of the concrete, and the result of the $0.3 \%$ fiber was the best. When $\alpha=1.121$ and $\beta=5.517$, the axial compressive stress-strain constitutive equation of PET fiber-reinforced coal gangue fine aggregate concrete was basically consistent with the experimental data. It can be seen that $\alpha=1.121$ and $\beta=5.517$ can be used as the parameters of the stress-strain constitutive equation of PET fiberreinforced coal gangue fine aggregate concrete

(5) In the discussion of the correlation of concrete mechanical properties, it was found that the splitting tensile strength of PET fiber-reinforced coal gangue fine aggregate concrete had a linear relationship with the axial compressive strength, the determination coefficient $R^{2}$ was 0.9875 , and the axial compressive strength and the cubic compressive strength also showed a linear relationship with the determination coefficient $R^{2}$ of 0.9327 . Through comparative analysis with the linear equation of coal gangue fine aggregate concrete, it was found that PET fiber has a significant effect on the linear relationship between split tensile strength and axial compressive strength

\section{Data Availability}

The data used to support the findings of this study are included within the article.

\section{Conflicts of Interest}

The authors declare that there are no conflicts of interest regarding the publication of this paper. 


\section{Acknowledgments}

This research was supported by the Research Fund for High Level Talents of Hubei University of Technology (Grant No. 337173).

\section{References}

[1] G. Huang, Y. Ji, J. Li, Z. Hou, and Z. Dong, "Improving strength of calcinated coal gangue geopolymer mortars via increasing calcium content," Construction and Building Materials, vol. 166, pp. 760-768, 2018.

[2] B. Jabłońska, A. V. Kityk, M. Busch, and P. Huber, "The structural and surface properties of natural and modified coal gangue," Journal of Environmental Management, vol. 190, pp. 80-90, 2017.

[3] Y. Guo, Q. Zhao, K. Yan, F. Cheng, and H. H. Lou, "Novel process for alumina extraction via the coupling treatment of coal gangue and bauxite red mud," Industrial \& Engineering Chemistry Research, vol. 53, no. 11, pp. 4518-4521, 2014.

[4] Z. C. Dong, J. W. Xia, C. Fan, and J. Cao, "Activity of calcined coal gangue fine aggregate and its effect on the mechanical behavior of cement mortar," Construction and Building Materials, vol. 100, pp. 63-69, 2015.

[5] X. Zhang, G. Wu, W. Yan, and D.'a. Liu, "Study on engineering performance of coal gangue fine aggregate concrete in Longdong area China building," Materials Science and Technology, vol. 28, no. 1, pp. 47-49, 2019.

[6] S. X. Zhou and S. M. Huang, "Effect of two kinds of activated coal gangue powder on compressive strength and pore size of blended cement mortars," Disaster Advances, vol. 3, pp. 397399, 2010.

[7] N. Zhang, H. H. Sun, X. M. Liu, and J. Zhang, "Early-age characteristics of red mud-coal gangue cementitious material," Journal of Hazardous Materials, vol. 167, no. 1-3, pp. 927932, 2009.

[8] M. Zhou, Y. W. Dou, Y. Z. Zhang, Y. Zhang, and B. Zhang, "Effects of the variety and content of coal gangue coarse aggregate on the mechanical properties of concrete," Construction and Building Materials, vol. 220, pp. 386-395, 2019.

[9] D. Wu, B. G. Yang, and Y. C. Liu, "Pressure drop in loop pipe flow of fresh cemented coal gangue-fly ash slurry: experiment and simulation," Advanced Powder Technology, vol. 26, pp. 920-927, 2015.

[10] H. J. Wu and L. D. Wang, "Shape effect of microstructured $\mathrm{CeO}_{2}$ with various morphologies on $\mathrm{CO}$ catalytic oxidation," Catalysis Communications, vol. 12, no. 14, pp. 1374-1379, 2011.

[11] B. C. Zheng, H. Q. Zhou, and R. J. He, "Experimental research on coal gangue paste filling material," Journal of Mining and Safety Engineering, vol. 4, pp. 460-463, 2006.

[12] T. Qi, G. Feng, Y. Li et al., "Effects of fine gangue on strength, resistivity, and microscopic properties of cemented coal gangue backfill for coal mining," Shock and Vibration, vol. 2015, 11 pages, 2015.

[13] L. Li, G. Long, C. Bai, K. Ma, M. Wang, and S. Zhang, "Utilization of coal gangue aggregate for railway roadbed construction in practice," Sustainability, vol. 12, no. 11, p. 4583, 2020.

[14] Z. Yuzhuo, Q. Wang, Z. Mei, F. Yanfeng, and Z. Zhikuan, "Mechanical properties of concrete with coarse spontaneous combustion gangue aggregate (SCGA): experimental investi- gation and prediction methodology," Construction and Building Materials, vol. 255, article 119337, 2020.

[15] Q. Yang, M. Lü, and Y. Luo, "Effects of surface-activated coal gangue aggregates on properties of cement-based materials," Journal of Wuhan University of Technology-Mater. Sci. Ed, vol. 28, no. 6, pp. 1118-1121, 2013.

[16] Z. Wang and N. Zhao, "Influence of coal gangue aggregate grading on strength properties of concrete," Wuhan University Journal of Natural Sciences, vol. 20, no. 1, pp. 66-72, 2015.

[17] J. Qiu, Y. Zhou, N. I. Vatin, X. Guan, S. Sultanov, and K. Khemarak, "Damage constitutive model of coal gangue concrete under freeze-thaw cycles," Construction and Building Materials, vol. 264, p. 120720, 2020.

[18] G. Xiao, C. Jixi, Q. Jisheng, Y. Gao, and J. Gao, "Damage evaluation method based on ultrasound technique for gangue concrete under freezing-thawing cycles," Construction and Building Materials, vol. 246, 2019.

[19] X. Guan, J. Qiu, H. Song, Q. Qin, and C. Zhang, "Stress-strain behaviour and acoustic emission characteristic of gangue concrete under axial compression in frost environment," Construction and Building Materials, vol. 220, pp. 476-488, 2019.

[20] D. Luo, Y. Wang, S. Zhang, D. Niu, and Z. Song, "Frost resistance of coal gangue aggregate concrete modified by steel fiber and slag powder," Applied Sciences, vol. 10, no. 9, p. 3229, 2020.

[21] Y. Wang, J. Qiu, W. Deng, J. Xing, and J. Liang, "Factors affecting brittleness behavior of coal-gangue ceramsite lightweight aggregate concrete," Frontiers in Materials, vol. 7, p. 333, 2020.

[22] D. M. Nguyen, V. Thi Nhung, T. M. L. Nguyen et al., "Synergistic influences of stearic acid coating and recycled PET microfibers on the enhanced properties of composite materials," Materials, vol. 13, no. 6, p. 1461, 2020.

[23] Y.-L. Bai, Z.-W. Yan, T. Ozbakkaloglu, J.-G. Dai, J.-F. Jia, and J.-B. Jia, "Dynamic behavior of PET FRP and its preliminary application in impact strengthening of concrete columns," Applied Sciences, vol. 9, no. 23, 2019.

[24] E. L. Pereira, A. L. de Oliveira Junior, and A. G. Fineza, "Optimization of mechanical properties in concrete reinforced with fibers from solid urban wastes (PET bottles) for the production of ecological concrete," vol. 149, pp. 837-848, 2017.

[25] J. M. Irwan, R. M. Asyraf, N. Othman, K. H. Koh, M. M. Annas, and S. K. Faisal, "The mechanical properties of PET fiber reinforced concrete from recycled bottle wastes," Advanced Materials Research, vol. 2602, pp. 347-351, 2013.

[26] M. Nematzadeh, A. A. Shahmansouri, and M. Fakoor, "Postfire compressive strength of recycled PET aggregate concrete reinforced with steel fibers: optimization and prediction via RSM and GEP," Construction and Building Materials, vol. 252, article 119057, 2020.

[27] J. Fayaz, C. Y. Adarsha, T. Raghavendra, B. C. Udayashankar, and K. Natarajan, "Structural behavior of concrete beams and columns reinforced with waste plastic incorporated GFRP (WPGFRP) rebars," Journal of Building Engineering, vol. 23, pp. 172-184, 2019.

[28] Y. D. Blanco, E. C. M. Campos, C. I. R. Valdés, and J. U. Chavarín, "Effect of recycled PET (polyethylene terephthalate) on the electrochemical properties of rebar in concrete," International Journal of Civil Engineering, vol. 18, no. 5, pp. 487$500,2020$. 
[29] T. Ochi, S. Okubo, and K. Fukui, "Development of recycled PET fiber and its application as concrete-reinforcing fiber," Cement and Concrete Composites, vol. 29, no. 6, pp. 448-455, 2007.

[30] T. K. M. Ali, "Shear strength of a reinforced concrete beam by PET fiber," Environment, Development and Sustainability, 2020, (prepublish).

[31] F. S. Khalid, J. M. Irwan, M. H. W. Ibrahim, N. Othman, and S. Shahidan, "Performance of plastic wastes in fiberreinforced concrete beams," Construction and Building Materials, vol. 183, pp. 451-464, 2018.

[32] A. H. Alani, N. M. Bunnori, A. T. Noaman, and T. A. Majid, "Mechanical characteristics of PET fibre-reinforced green ultra-high performance composite concrete," European Journal of Environmental and Civil Engineering, no. article 1772117, 2020.

[33] A. I. Al-Hadithi, A. T. Noaman, and W. K. Mosleh, "Mechanical properties and impact behavior of PET fiber reinforced self- compacting concrete (SCC)," Composite Structures, vol. 224, article 111021, 2019.

[34] M. Fadadu, N. Vadher, V. Trivedi, M. Mungule, and K. K. R. Iyer, "A comparative study on stress-strain response and associated hysteresis for conventional and PET macro-reinforced concrete," Construction and Building Materials, vol. 264, article 120534, 2020.

[35] A. A. Mohammed and A. A. F. Rahim, "Experimental behavior and analysis of high strength concrete beams reinforced with PET waste fiber," Construction and Building Materials, vol. $244,2020$.

[36] B. L. Yan, L. Z. Jiang, Z. M. Xiao et al., Gb 175-2007 Common Portland Cement, Chinese Standard Press, Shenzhen, China, 2007.

[37] L. K. Cheng, Z. X. Duan, Q. C. Liu et al., Gb 50086-2001 Specifications for Bolt-Shotcrete Support, Chinese Standard Press, Shenzhen, China, 2001.

[38] W. Ding, F. G. Leng, J. Huo et al., JGJ 63-2006 Water Standard for Concrete, Chinese Standard Press, Shenzhen, China, 2006.

[39] J. W. Rong, J. W. Lu, Y. Yao et al., Gb/t 50081-2002 Standard for Test Method of Mechanical Properties on Ordinary Concrete, Chinese Standard Press, Shenzhen, China, 2002.

[40] A. Wang, Y. Zhu, H. Xu, K. Liu, Y. Jing, and D. Sun, "Research progress of gangue aggregate for concrete," Silicate bulletin, vol. 38, no. 7, pp. 2076-2086, 2019.

[41] S. Zeng, G. Wang, and X. Bi-Gan, "Experimental study on mix proportion design of lightweight aggregate concrete," New building materials, vol. 40, no. 10, pp. 55-57, 2013.

[42] Z. Guo and X. Shi, Principle and Analysis of Reinforced Concrete, Tsinghua University Press, Beijing, 2003.

[43] Z. Li, G. Wang, S. Yang, and G. Ju, "Experimental study on mechanical properties and stress-strain constitutive relationship of desert sand concrete," Journal of applied mechanics, vol. 36, no. 5, 2019.

[44] Z. Chen, C. Zhou, Y. Chen, and J. Huang, "Mechanical properties and stress-strain constitutive relationship of recycled pebble aggregate concrete," Journal of applied foundation and Engineering Sciences, vol. 22, no. 4, pp. 763-774, 2014.

[45] Z. Chen, C. Zhou, D. Xu et al., "Influence of aggregate type on mechanical properties of recycled concrete," Journal of applied mechanics, vol. 34, no. 1, pp. 180-185, 2017.
[46] J. D. Zhao, Y. L. Xu, X. K. Huang et al., Gb 50010-2010 Code for Design of Concrete Structures, Chinese Standard Press, Shenzhen, China, 2010.

[47] Z. Yonggang, T. Jun, L. Raoping et al., "Application of an enhanced BP neural network model with water cycle algorithm on landslide prediction," Stochastic Environmental Research and Risk Assessment, vol. 27, pp. 1-9, 2020.

[48] Z. Yonggang, T. Jun, H. Zhengying, T. Junkun, and L. Chao, "A novel displacement prediction method using gated recurrent unit model with time series analysis in the Erdaohe landslide," Natural Hazards, 2020.

[49] Z. Yonggang and Y. Lining, "A novel dynamic predictive method of water inrush from coal floor based on gated recurrent unit model," Natural Hazards, 2020.

[50] Y. Zhang, Z. Zhang, S. Xue, R. Wang, and M. Xiao, "Stability analysis of a typical landslide mass in the Three Gorges Reservoir under varying reservoir water levels," Environmental Earth Sciences, vol. 79, no. 1, 2020.

[51] Z. H. A. N. G. Yonggang, Z. H. U. Shuyun, T. A. N. Junkun, L. I. Lidan, and Y. I. N. Xiangjie, "The influence of water level fluctuation on the stability of landslide in the Three Gorges Reservoir," Arabian Journal of Geosciences, vol. 13, p. 845, 2020.

[52] Z. Yonggang, Z. Shuyun, Z. Weiqiang, and L. Hui, “Analysis of deformation characteristics and stability mechanisms of typical landslide mass based on the field monitoring in the Three Gorges Reservoir, China," Journal of Earth System Science, vol. 128, no. 1, p. 9, 2019.

[53] G. Bin, J. Yujing, Y. Ping, and Z. H. A. N. G. Sunhao, "Discrete element numerical simulation of mechanical properties of methane hydrate-bearing specimen considering deposit angles," Journal of Natural Gas Science and Engineering, vol. 76, article 103182, 2020.

[54] B. Gong, J. I. A. N. G. Yujing, and C. Lianjun, "Feasibility investigation of the mechanical behavior of methane hydratebearing specimens using the multiple failure method," Journal of Natural Gas Science and Engineering, vol. 69, p. 102915, 2019. 